some of his study animals. Ecological factors considered include not only climate, flora and territory and the inter-relationship of the animals, but what is of far greater importance in the Indian context, the impact of man.

Descriptions of the study areas precede the discussion on the problems of 33 wild mammals in coming, or failing to come, to terms with their shrinking and ravaged habitats. Some, like the lion-tailed monkey, tiger, wild buffalo, blackbuck and barasingha, have suffered grievously; a few like elephant and chital have adapted bravely. But it could be that the worst is still to come. There are extended sections on elephant and gaur, on which Krishnan's knowledge in peninsular India is unrivalled. $\mathrm{He}$ concludes inescapably that the effect of human disturbance on the wildlife and plants today has been overwhelming, but, sadly, is still the least appreciated major factor in conservation in India.

I had read the reports as they had been published; reading them again the integrity of the research and of the presentation of results made as deep an impression as before.

B. SESHADRI

The Handbook of British Mammals, 2nd edition, edited by G. B. Corbet and H. N. Southern. Blackwell Scientific Publications, for the Mammal Society, $£ 9.75$.

The first edition of this Handbook in 1964 so stimulated the study of our mammalian fauna during the next twelve years that the accumulated information makes the second edition more than twice as large. The original Part I on the biology of British mammals has been condensed to a chapter on the Study of British Mammals 1964-1976, in order to make room for the enormously expanded systematic accounts. The editors have enlisted a team of specialists to deal with the groups and species they have made their special study, and the result is a handbook unsurpassed in quality by any other covering a similar area.

Information about each species is set out on a standard plan so that reference to any point required is easily found. All the excellent photographs and drawings are selected to show important points in identification, structure or behaviour, not just as ornamental embellishments, and there is a distribution map for each species, except for the Cetacea. The text is well documented with references to original sources listed in voluminous bibliographies, and there is a full index as well as a short glossary of words not found in the Concise Oxford Dictionary.

It might be thought that a handbook of this nature would be useful for reference but too formalised for straightforward perusal. On the contrary, the systematic accounts, in addition to the introductory chapter, make fascinating reading for any naturalist. The editors, contributors, and publishers are to be congratulated on producing a splendid book that will remain a standard for many years.

L. HARRISON MATTHEWS

\title{
The Savage Paradise: the Predators of Serengeti, by Hugo van Lawick. Collins,
} $£ 15$.

This is a wonderful book, concerned mainly with portraying the predators of the Serengeti and the Ngorongoro Crater in their favoured habitats. The author has worked as a wildlife photographer in this region over a period of 15 years, and is widely known for the skill and sensitivity with which he uses his camera. Years and years of sitting quietly watching animals all day long have given him an extensive knowledge of their behaviour, what the pattern is and what follows in sequence; he has developed a strong and almost intuitive sense of what will happen next. This faculty of anticipation and timing is one reason why his animal pictures are outstanding, as demonstrated by the 150 in this book, almost all in colour, which represent the pick of goodness knows how many taken over the years.

In planning the book, Collins clearly rose to the challenge and set out to provide a setting worthy of the pictures: fine thick paper, ultra-large pages, excellent colour 
reproduction and printing, gratifyingly carried out in England, and the whole imaginatively laid out and unified by the designer, Linda Sullivan. No lettering has been allowed to trespass on the picture pages; instead, short descriptive notes on each photograph are banished to a separate index with a black-and-white miniature to identify it by. In addition, 40 pages of informatory text describe the predators and the author's experiences photographing them.

I suppose some day a better picture book than this may come out of the Serengeti, but not, I would think, for many years to come. All who share the author's love for the place will find, even at $£ 15$, that it is well worth the price for the memories it will evoke now and in the years ahead.

JOHN OWEN

\section{Animals on View, by Anthony Smith. Weidenfeld \& Nicolson, $£ 6.50$.}

As the title page states, this is an illustrated guide to Britain's Safari Parks, Zoos, Aquariums and Bird Gardens. In gathering his encyclopaedic information, Anthony Smith travelled 3000 miles and visited every major animal collection within Britain, 180 in all. Tabulated information is given for each: how to get there; opening hours; feeding arrangements for inmates and visitors; attractions and facilities. A descriptive story follows, mentioning the more noteworthy species and the breeding record, and there are numerous black and white illustrations and maps, and some striking colour photographs.

The present reviewer feels a certain embarrassment at seeing animals in captivity. Not so the present author. His awareness that some collections have failed to keep up with rapidly changing standards, that traces of the old menagerie linger on and that gate money dominates, scarcely dampens his enthusiastic approval: 'Having accused zoos and zoo-men of a wide variety of colourful drawbacks, such as dishonesty, hypocrisy, in-fighting, secrecy and mere illegality, I should hasten to add that I am entirely on their sides'. His overall objective, he says, is 'to tell something of the flavour of each collection, of its uniqueness, its charms (or horrors) and of its particular animal offerings'. Above all, he brings out the revolution of the last half-century-Whipsnade in 1931, Longleat in 1949 and their proliferating successors.

Affluence here, population explosion there, the motor vehicle everywhere, have together altered irreversibly the prospects for animals in the wild. Some zoos are becoming more like nature reserves, some nature reserves more like zoos. More and more species will survive only within the confines of one or other. Like it or not, the new 'zoos' are the progeny of our civilisation. We had better recognise our children and see that they are brought up properly.

G. T. CORLEY SMITH

\section{Natural History in America-from Mark Catesby to Rachel Carson, by Wayne Hanley. Quadrangle/New York Times Book Co, £8.95.}

This is a lovely book, most scholarly and packed with information. It could so easily have been one of those anthologies where a few introductory words preface each slab of prose. Instead, at least fifty per cent consists of learned Mr Hanley telling us a very great deal about the thirty or so principal characters he has selected from the 250 years of active American natural history. All the big names are here-Audubon, Wilson, Bartram, Thoreau, Melville, Agassiz, Gray, Roosevelt, Fuertes, Bachman, Wilkesbut not a single foreigner. In other words, this is a series of biographies of the principal Americans who have contributed to American natural history in particular. The quotations may be twenty pages, or a paragraph, but have been chosen both to illustrate the natural historian in question and to portray the prevailing state of natural history in general. Sometimes it is difficult for the reader to change gear, to slip from late twentieth-century style into its variety of predecessors (and even Melville can be heavy going), but a willingness to skip the indented sections may be no more than additional praise for the author. Regrettably, he must also join the list of those 